\title{
A COISA JULGADA DE QUESTÃO PREJUDICIAL NO CPC15 E 0 PRINCÍPIO DISPOSITIVO ${ }^{1}$
}

\section{THE RES JUDICATA THING OF PREJUDICIAL QUESTIONIN CPC15 AND THE DISPOSITIVE PRINCIPLE}

Luan Eduardo Steffler Mestrando em Direito pela Universidade Federal de Santa Catarina - UFSC. Pós-Graduado em Direito Processual pela Pontifícia Universidade Católica de Minas Gerais - PUCMG. Advogado. Bolsista de Pesquisa de Mestrado do Programa CNPq. Florianópolis/SC. E mail:luan.eduardo.steffler@gmail.com

Rafael Niebuhr Maia de Oliveira Mestrando em Direito pela Universidade Federal de Santa Catarina - UFSC. Pós-Graduado em Direito Processual pela UNIDERP. Coordenador de cursos de pós-graduação em Direito da UNIFEBE, onde também atua como professor no curso de graduação em Direito. Professor convidado em diversos cursos de pós-graduação lato senso em Direito (UNIVALI, AMATRA12, ENA, ESA/SC, INPG, Instituo Valor Humano, Excelsu Educacional). Advogado. Conselheiro Estadual da $\mathrm{OAB} / \mathrm{SC}$ gestão 2019/2021. E-mail: rafaelmaiaadv@gmail.com

RESUMO: Trata-se de pesquisa qualitativa exploratória, de procedimento monográfico, de abordagem dedutiva, objetivando analisar as modificações implementadas pelo CPC15 nos limites objetivos da coisa julgada material, mais especificamente quanto a possibilidade de sua extensão as questões prejudiciais, independentemente de ação

\footnotetext{
${ }^{1}$ Artigo recebido em 24/06/2020 e aprovado em 10/03/2021.
} 
declaratória incidental, com o escopo de perquirir se tal mudança representaria ofensa ao princípio dispositivo. Com base nas fontes adotadas e a partir de uma análise história do instituto e com espeque em semelhante instrumento processual estrangeiro do colateral estoppel, pode-se afirmar que a legislação atual tomou as precauções necessárias para evitar que as notadas vantagens advindas da maior celeridade, eficiência e redução na possibilidade de decisões logicamente contraditórias não fossem conquistadas as custas dos princípios democráticos do processo, especialmente no que tange a necessidade de contraditório prévio e efetivo como condicionante desta possibilidade, pelo que não se verifica ofensa ao princípio dispositivo.

PALAVRAS-CHAVE: Coisa julgada; CPC15; princípio dispositivo; questão prejudicial; direito comparado.

\begin{abstract}
This is an exploratory qualitative research, with a monographic procedure, with a deductive approach, aiming to analyze the changes implemented by CPC15 in the objective limits of res judicata, more specifically regarding the possibility of its extension to prejudicial question, regardless of incidental declaratory action, with the scope of investigating whether this change would represent an offense to the dispositive principle. Based on the sources adopted and based on a historical analysis of the institute and based on a similar foreign procedural instrument in the colateral estoppage, it can be said that the current legislation has taken the necessary precautions to prevent the perceived advantages arising from greater speed, efficiency and reduction in the possibility of logically contradictory decisions were not achieved at the expense of the democratic principles of the process, especially with regard to the need for a previous and effective contradiction as a condition of this possibility, so there is no offense to the dispositive principle.
\end{abstract}

KEYWORDS: Res judicata; CPC15; dispositive principle; prejudicial question; comparative law.

\title{
1. INTRODUÇÃO
}


O CPC15 reformulou de maneira bastante ampla o anterior diploma processual brasileiro, buscando enquadrar o processo nas premissas da Constituição Federal da República, de maneira a efetivar os princípio e normas fundamentais nela inseridos. Em seus primeiros dispositivos, o legislador ratificou os compromissos fundamentais que o Código de Processo deve seguir, como a liberdade, igualdade a tutela tempestiva e a boafé.

Outro ponto crucial implementado pelo novel diploma, foi o dever de cooperação com as partes, presente no art. $6^{\circ}$. Desta maneira, passamos a vivenciar um processo democrático de direito, pautado no dever de cooperação com as partes, incluindo nessa obrigação o próprio magistrado.

Dentro deste novo sistema, ocorreram diversas mudanças no que tange ao instituto das preclusões, como também no âmbito da coisa julgada, pautadas em perspectivas dinâmicas e cooperativas. Assim, os arts. 503 a 506, passaram a disciplinar o tema, apresentando novos limites objetivos e subjetivos da julgada. Consequentemente, o que era protegido pela coisa julgada mudou, se antes apenas o objeto principal da ação era por ela afetada, agora todas as questões discutidas pelas partes dentro do próprio processo, respeitados determinados requisitos, podem ser afetadas pela coisa julgada material. Além disso, previu-se a ampliação subjetiva dos efeitos da coisa julgada, permitindo que terceiros poderão ser dela beneficiados.

Diante dos novos rumos impostos pelo CPC15, o objetivo da pesquisa centra-se em analisar as modificações implementadas nos limites objetivos da coisa julgada material, mais especificamente quanto a possibilidade de sua extensão as questões prejudiciais, independentemente de ação declaratória incidental, com o escopo de perquirir se esta mudança representaria ofensa ao princípio dispositivo.

Para tanto, utilizar-se-á de pesquisa qualitativa exploratória, de procedimento monográfico, de abordagem dedutiva e técnica de pesquisa bibliográfica, por meio da qual buscar-se-á apresentar uma revisão histórica do instituto ao longo das reformas ocorridas no CPC desde o código de 1939, para na sequência abordar o instituto processual do collateral estoppel, presente no sistema da Common Law, no direito 
estadunidense, com o intuito de traçar as similitudes deste modelo com o modelo brasileiro, no que tange a coisa julgada nas questões prejudiciais.

\section{COISA JULGADA E PREJUDICIAIS DE MÉRITO}

Ao estabelecer um conceito operacional para questões processuais, Hoffmann Junior busca inspiração em Theodoro Junior e Ovídio Baptista, ao defini-las como pontos controvertidos envolvendo os fatos e regras jurídicas debatidas entre as partes, e que se diferenciam dos motivos/fundamentos da decisão, em razão de "seu caráter pressuposto, na medida em que sua ausência, ou modificação, implicaria, necessariamente, na alteração do raciocínio imposto pelo juiz."2

Pode-se definir a questão prejudicial como aquele provimento de cuja solução dependerá não a possibilidade nem a forma do pronunciamento sobre a outra questão, mas o teor desse pronunciamento. A segunda questão é ligada a primeira, não no seu ser, todavia no seu modo de ser. ${ }^{3}$ Assim, a questão prejudicial se põe como matéria que necessariamente deverá ser julgada para que o pedido principal o seja. ${ }^{4}$

As questões prejudiciais são aquelas de direito material ou processual, capazes de influenciarem diretamente na resolução do mérito. Não impedem nem postergam o exame do mérito, mas de certa forma, condicionam o sentido no qual ele deve ser resolvido. Ao manejarem, o modo de ser (e não ser) da questão principal, as prejudiciais caracterizam-se não de qualquer questão prévia, mas somente daquelas que se qualificam como um antecedente lógico e verdadeiramente necessário à solução do mérito. ${ }^{5}$

A comum confusão entre questões preliminares e prejudiciais pode ser solucionada pela lição segundo a qual, o que distingue as questões preliminares das prejudiciais não é seu conteúdo, mas sim os efeitos que são capazes de produzir com

\footnotetext{
${ }^{2}$ HOFFMANN JUNIOR, Lírio. A teoria da substanciação e seus reflexos sobre a coisa julgada. Panorama atual do novo CPC. Coordenadores: Paulo Henrique dos Santos Lucon e Pedro Miranda de Oliveira. 1. Ed. Florianópolis: Empório do Direito, 2016. p. 263.

${ }^{3}$ MOREIRA, José Carlos Barbosa. "Questões prejudiciais e questões preliminares". Direito Processual Civil - ensaios e pareceres. Rio de Janeiro: Borsoi, 1971, p. 83.

${ }^{4}$ MINAMI, Marcos Youji; PEIXOTO, Ravi. Da questão prejudicial incidental constitucional no STF e o novo regime de coisa julgada. Revista Jurídica da Seção Judiciária de Pernambuco, (10), 277-302. p. 286. ${ }^{5}$ REDONDO, Bruno Garcia. Questões prejudiciais e limites objetivos da coisa julgada no novo CPC. Revista de Processo, São Paulo; RT, a.40, v. 248, out. 2015. p. 47-48.
} 
relação ao objeto principal do pedido. Desse modo, enquanto as questões preliminares são capazes de obstar a análise da questão subordinada, mas sem nada dizer a seu respeito; a questão prejudicial influi diretamente no conteúdo da questão subordinada, de modo que "Da solução da questão subordinante, depende o conteúdo ou o sentido que se quer dar à questão subordinada." 6

Importante diferenciar questões prejudiciais, que se manifestam dentro da mesma relação processual, das causas prejudiciais, que reluzem quando a sentença a ser proferida em um processo seja apenas um dos elementos de ligação necessário ao raciocínio do juízo em outro. Desta maneira, para que possa ocorrer tal modalidade em relação as questões prejudicais, imprescindível que ocorram ambos processos concomitantes, desconsiderando-se o período de tempo. Consequentemente, se já tiver ocorrido julgamento no processo subordinante, não há que se falar em causa prejudicial, mas em mero ponto a ser assimilado pelo juízo da demanda subordinada. ${ }^{7}$

Em síntese, pode-se definir a questão de modo que o objeto da causa seria prejudicial se houvesse similitude na tramitação dos processos, transformando-se em ponto com o arremate da causa subordinada. Importante frisar, que a questão prejudicial sempre ingressa no processo prejudicado na forma de ponto, ou seja, tema no qual inexiste controvérsia, pois está já teria sido decidida no processo prejudicial, podendo envolver o mesmo juízo, as mesmas partes e seguir o mesmo rito processual, mas isso não ocorrerá necessariamente. $^{8}$

\section{COISA JULGADA E QUESTÕES PREJUDICIAIS NO CPC73}

Com a entrada em vigor do diploma processual de 1973 e diante da incerteza que rodeava a coisa julgada nas questões prejudiciais no CPC39, o legislador positivou de forma rígida e clara, no art. $469^{9}$, que a coisa julgada abrangeria somente a parte

\footnotetext{
${ }^{6}$ MINAMI, Marcos Youji; PEIXOTO, Ravi. Da questão prejudicial incidental constitucional no STF e o novo regime de coisa julgada. Revista Jurídica da Seção Judiciária de Pernambuco, (10), 277-302. p. 284.

${ }^{7}$ MENESTRINA, Francesco. La pregiudiciale nel processo civile. Milano: Giuffrè, 1963. p. 102.

${ }^{8}$ MENESTRINA, Francesco. La pregiudiciale nel processo civile. Milano: Giuffrè, 1963. p. 153.

${ }^{9}$ CPC73: Art. 469. Não fazem coisa julgada:

I - os motivos, ainda que importantes para determinar o alcance da parte dispositiva da sentença;

Il - a verdade dos fatos, estabelecida como fundamento da sentença;

III - a apreciação da questão prejudicial, decidida incidentemente no processo.
} 
dispositiva da sentença de mérito, no qual dizia respeito apenas às pretensões formuladas pelas partes. ${ }^{10}$

Portanto, na seara do CPC73 não houve divergências de que apenas a decisão a respeito do pedido principal era atingido pela coisa julgada material. Rotineiramente, afirmava-se que as questões prejudiciais eram enfrentadas ou analisadas, mas de maneira alguma decididas, pois somente o pedido (questão principal) seria objeto de decisão jurisdicional. ${ }^{11}$

Além do mais, o art.470 ${ }^{12}$ do CPC73 disciplinava delineadamente que somente o requerimento da parte, contido na ação declaratória incidental, na forma dos arts. $5^{\circ} \mathrm{e}$ 325, permitiria que a questão prejudicial, desse modo resolvida, pudesse ser acobertada pela coisa julgada. Entretanto, diante desse deslinde legislativo, a doutrina passou a defender, a restrição da res judicata ao capítulo dispositivo da sentença. ${ }^{13}$

Na sistemática daquele código, para que adquirisse status de coisa julgada a questão prejudicial deveria ser transformada em principal, por meio de pedido específico, que se dava por meio da então chamada ação declaratória incidental. ${ }^{14}$ No bojo dessa ação, a decisão proferida pelo magistrado ficava acobertada pela coisa julgada, uma vez que a questão deixava de ser fundamento para um pedido principal, para se transformar no objeto principal da decisão do magistrado. ${ }^{15}$

Tal teoria restritiva, obtinha o viés eminentemente privatista. Pois, caberia às partes o encargo da determinação dos pedidos e, consequentemente, dos limites objetivos da coisa julgada. Desta maneira, ocorria forte correspondência entre os pedidos deduzidos

\footnotetext{
${ }^{10}$ MOREIRA, José Carlos Barbosa. Coisa julgada - limites objetivos. In: Direito aplicado, vol. II, Rio de Janeiro, 2000, p. 448

${ }^{11}$ REDONDO, Bruno Garcia. Questões prejudiciais e limites objetivos da coisa julgada no novo CPC. Revista de Processo, São Paulo; RT, a.40, v. 248, out. 2015. p. 49.

12 CPC73: Art. 470. Faz, todavia, coisa julgada a resolução da questão prejudicial, se a parte o requerer

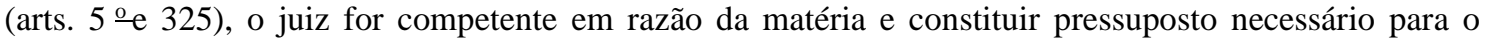
julgamento da lide

13 ALVIM, Arruda. Ação declaratória incidental. In: WAMBIER, Luiz Rodrigues; WAMBIER, Teresa Arruda Alvim (Org.). Doutrinas Essenciais Processo Civil. v. II. São Paulo: Revista dos Tribunais, 2011, p. 760.

${ }^{14}$ REDONDO, Bruno Garcia. Questões prejudiciais e limites objetivos da coisa julgada no novo CPC. Revista de Processo, São Paulo; RT, a.40, v. 248, out. 2015. p. 50.

${ }^{15}$ DIDIER JR., Fredie. Extensão da coisa julgada à resolução da questão prejudicial incidental no novo Código de Processo Civil brasileiro. Civil Procedure Review, v.6, n.1, p.94, 2015.
} 
pelas partes e as questões nas quais seriam naturalmente imutabilizadas, em clara homenagem ao princípio dispositivo. ${ }^{16}$

\section{COISA JULGADA E QUESTÕES PREJUDICIAIS SOB A ÉGIDE DO CPC15}

De maneira significativa, houveram profundas transformações no regime da coisa julgada no $\mathrm{CPC} 15$, por meio dos parágrafos $1^{\circ}$ e $2^{\circ}$ do art. $503^{17}$, que modificaram o alcance da coisa julgada, ampliando seus limites objetivos.

O atual diploma processual, ao contrário do seu antecessor, passou a permitir a formação de coisa julgada material inclusive sobre questões prejudiciais que não possuem pedido específico de alguma das partes. Isto posto, pode-se concluir que as questões prejudiciais ganharam aptidão para se tornarem objeto da coisa julgada, sem que sejam transformadas em principais, desde que tenham sido expressamente debatidas pelas partes, apreciadas incidentalmente pelo juízo dotado de competência absoluta para resolvê-las e inexistam restrições probatórias ou limitações à cognição para o aprofundamento do debate sobre dita questão. ${ }^{18}$

Não obstante, o tema se tornou amplamente discutido pela doutrina, causando até mesmo certa perplexidade, angariando inexauríveis esforços. Pode-se fazer uma remissão a clássica abordagem de Friedrich Von Savagny, consagrada nos ensinamentos de Giuseppe Chiovenda ${ }^{19}$, discutida notadamente no século XIX, com os motivos da sentença classificados em subjetivos e objetivos. Subjetivos, seriam as razões que formam o convencimento pessoal do juiz, os quais o levam a decidir de determinada maneira sobre o direito submetido a sua apreciação cognitiva. Já os objetivos concernem aos elementos

\footnotetext{
${ }^{16}$ FABRÍCIO, Adroaldo Furtado. A ação declaratória incidental. Rio de Janeiro: Forense, 1976, p. 15

${ }^{17}$ CPC15: Art. 503. A decisão que julgar total ou parcialmente o mérito tem força de lei nos limites da questão principal expressamente decidida.

$\S 1^{\circ} \mathrm{O}$ disposto no caput aplica-se à resolução de questão prejudicial, decidida expressa e incidentemente no processo, se:

I - dessa resolução depender o julgamento do mérito;

II - a seu respeito tiver havido contraditório prévio e efetivo, não se aplicando no caso de revelia; III - o juízo tiver competência em razão da matéria e da pessoa para resolvê-la como questão principal. $\S 2^{\circ}$ A hipótese do $\S 1^{\circ}$ não se aplica se no processo houver restrições probatórias ou limitações à cognição que impeçam o aprofundamento da análise da questão prejudicial.

${ }^{18}$ REDONDO, Bruno Garcia. Questões prejudiciais e limites objetivos da coisa julgada no novo CPC. Revista de Processo, São Paulo; RT, a.40, v. 248, out. 2015. p. 50.

${ }^{19}$ CHIOVENDA, Giuseppe. Saggi di diritto processuale civile. v. II. Milano: Giuffrè, 1993.
} 
constitutivos da relação jurídica e ficariam cobertos pela coisa julgada. Todavia, também no século XIX, Francisco de Paula Batista, pugnou nomenclatura "motivos objetivos", mas sustentou que a coisa julgada somente acobertava o dispositivo das decisões.

Análogas as premissas apresentadas no século de XIX, pode-se perceber a divergência de opiniões rodeadas sobre o assunto, cuja solução exige uma análise aprofundada do direito positivo. Em relação a breve exposição de como era tratado as prejudiciais nos códigos passados, percebe-se a oscilação do legislador convergente ao tratamento da matéria. O código Buzaid, manifestou-se precisamente sobre o tema, excluindo de maneira taxativa o alcance da coisa julgada as prejudiciais que não fossem objeto de ação declaratória incidental, já o atual diploma processual optou por um caminho diverso.

Diante deste novo cenário processual, o parágrafo $1^{\circ}$ do art. 503 do $\mathrm{CPC} 15$, detém a regra de que, dentro de certas condições, a coisa julgada irá incidir sobre a resolução de questão prejudicial, decidida expressa e incidentemente no processo. ${ }^{20}$

Deve-se extrair de tal regra, que a mesma não constitui certa exceção ao que disciplina o art. 504 do $\mathrm{CPC} 15^{21}$, de modo que a decisão expressa da questão prejudicial, uma vez observados os pressupostos do parágrafos $1^{\circ}$ e $2^{\circ}$, faz coisa julgada precisamente, tratando-se de um comando sentencial e não de uma mera fundamentação. A coisa julgada não só recebe a autoridade de um decisum, como também produz todos os efeitos de um de um decisum. Meramente o que acontecerá na prática é que, em uma ação de petição de herança, haverá o reconhecimento de filiação. Desde que regularmente preenchidos os pressupostos examinados a seguir, tal reconhecimento fará coisa julgada e terá eficácia de um comando sentencial declaratório de filiação, podendo inclusive ser levado ao registro no cartório competente. ${ }^{22}$

\footnotetext{
${ }^{20}$ TALAMINI, Eduardo. Questões prejudiciais e coisa julgada. Informativo Justen, Pereira, Oliveira e Talamini, Curitiba, $\mathrm{n}^{\circ}$. 109, março de 2016, disponível em http://www.justen.com.br/informativo, acesso em 21 de maio de 2020. p.06.

${ }^{21}$ Art. 504. Não fazem coisa julgada:

I - os motivos, ainda que importantes para determinar o alcance da parte dispositiva da sentença;

II - a verdade dos fatos, estabelecida como fundamento da sentença.

22 TALAMINI, Eduardo. Questões prejudiciais e coisa julgada. Informativo Justen, Pereira, Oliveira e Talamini, Curitiba, $\mathrm{n}^{\circ}$. 109, março de 2016, disponível em http://www.justen.com.br/informativo, acesso em 21 de maio de 2020. p.06.
} 
Pode-se reputar tal mudança legislativa, tanto ao escopo da simplicidade procedimental e economia processual, quanto na intenção de coibir a contradição lógica que até então se possibilitava na medida em que determinada questão discutida em um processo poderia ser rediscutida em outro processo, obtendo solução diversa. ${ }^{23}$

Ao eliminar a necessidade de propositura de ação declaratória incidental, embora autorizada doutrina entenda pela sua possibilidade no sistema atual ${ }^{24}$, o novo sistema aposta no mecanismo do contraditório prévio e efetivo aliado a expressa previsão legal, como forma de substituir o sistema anterior, garantindo ao mesmo tempo a previsibilidade jurídica e a concretização dos princípios da economia e eficiência processual ${ }^{25}$ :

A extensão da coisa julgada às questões prejudiciais incidentalmente decididas traz, potencialmente, alguns benefícios. Dentre eles estão o maior aproveitamento dos processos, a prevenção de rediscussões a respeito de questões prejudiciais já decididas e a homogeneização das respostas jurisdicionais, evitando decisões conflitantes sobre o mesmo tema. ${ }^{26}$

Essa modificação legislativa é capaz de produzir efeitos práticos em demandas que povoam os corredores do foro, como no caso de pedidos de repetição de indébito que pressupõem previa declaração de nulidade de cláusulas contratuais, ou pedidos de exclusão de nomes do cadastro de devedores, dos quais depende a declaração de inexistência de débito, dentre outras cláusulas que poderão ser impactadas de acordo com a aplicação que se der ao disposto nos parágrafos $2^{\circ}$ e $3^{\circ}$ do art. 503 do CPC $15 .{ }^{27}$

\subsection{Primeiro pressuposto: Questão que se apresente como prejudicial}

O respectivo pressuposto está disciplinado no art. 503, parágrafo $1^{\circ}$ do $\mathrm{CPC} 15$. Exige-se, inicialmente, que o ponto da questão prejudicial se transforme em questão, ou

\footnotetext{
${ }^{23}$ MINAMI, Marcos Youji; PEIXOTO, Ravi. Da questão prejudicial incidental constitucional no STF e o novo regime de coisa julgada. Revista Jurídica da Seção Judiciária de Pernambuco, (10), 277-302. p. 285. ${ }^{24}$ REDONDO, Bruno Garcia. Questões prejudiciais e limites objetivos da coisa julgada no novo CPC. Revista de Processo, São Paulo; RT, a.40, v. 248, out. 2015.

${ }^{25}$ REICHELT, Luis Alberto. "Decisão sobre questões prejudiciais de mérito e direito fundamental à intangibilidade da coisa julgada material no novo Código de Processo Civil." Revista de Processo. No. 259. 2016. p. 5.

${ }^{26}$ DE LUCCA, Rodrigo Ramina. Os limites objetivos da coisa julgada no novo Código de Processo Civil. Revista de Processo. vol, 2016, 252. p.15.

${ }^{27}$ REICHELT, Luis Alberto. "Decisão sobre questões prejudiciais de mérito e direito fundamental à intangibilidade da coisa julgada material no novo Código de Processo Civil." Revista de Processo. No. 259. 2016. p. 8.
} 
seja, que o ponto seja realmente controvertido. Assim, somente haverá coisa julgada se existir dissenso entra as partes sobre determinado tema, ou ao menos que seja por uma parte alegado e permitido a parte contrária contrapô-la. Exaurido a controvérsia, questão não haverá, desta maneira o ponto prejudicial não será acobertado pela coisa julgada material. $^{28}$

A questão será prejudicial, se encarada naquele processo como questão subordinada. Desta forma, não bastará para a caracterização da prejudicialidade a simples antecedência de uma questão em relação à outra. ${ }^{29}$

Ressalta-se, que não formam coisa julgada os motivos (ainda que importantes para determinar o alcance da decisão), como também a verdade dos fatos (conhecida como fundamento da sentença), por força do impedimento do art. 504, incisos I e II, do $\mathrm{CPC}^{3} 5^{30}$. Da mesma maneira, não há coisa julgada sobre a ratio decidendi, mais conhecida como a tese jurídica que sustenta a decisão. ${ }^{31}$

Ocorre que, a doutrina já manifestou certo debate a respeito de qual questão resolvida no processo seja considerada prejudicial, ensejando o acobertamento pela coisa julgada. Uma primeira corrente defende que apenas a questão que deu causa a decisão seria estabilizada. Consequentemente, se em uma determinada ação de pedido de herança por filho ilegítimo na qual é decidido que o autor é realmente filho do de cujus, porém a causa é julgada improcedente, não havendo bens a serem herdados, a decisão envolvendo a filiação não seria considerada prejudicial, de maneira a não formar coisa julgada, visto que não foi o que deu causa a decisão. Desta interpretação, pode se extrair que somente ao final do processo se descobriria se a questão prejudicial albergará a coisa julgada. ${ }^{32}$

Contraposto, a outra corrente, que aparenta seguir mais detalhadamente os anseios do CPC15, defende que a questão pode ser protegida pela coisa julgada caso se

${ }^{28}$ WAMBIER, Teresa Arruda Alvim; CONCEIÇÃO, Maria Lúcia Lins; RIBEIRO, Leonardo Ferre da Silva; MELLO, Rogerio Liscastro Torres de. Primeiros comentários ao novo Código de Processo Civil: artigo por artigo. São Paulo: RT, 2015, p. 823.

${ }^{29}$ MARINONI, Luiz Guilherme; ARENHART, Sérgio Cruz; MITIDIERO, Daniel. Novo Código de Processo Civil Comentado. 1. ed. Ver. Atual e ampl. São Paulo: Revista dos Tribunais, 2017. p. 616.

${ }^{30}$ WAMBIER, Teresa Arruda Alvim; CONCEIÇÃO, Maria Lúcia Lins; RIBEIRO, Leonardo Ferre da Silva; MELLO, Rogerio Liscastro Torres de. Primeiros comentários ao novo Código de Processo Civil: artigo por artigo. São Paulo: RT, 2015, p. 824.

${ }^{31}$ DIDIER jr., Fredie; BRAGA, Paulo Sarno; OLIVEIRA, Rafael. Curso de Direito Processual Civil. 10.ed. Salvador: JUSPodivm, 2015, v.2. p. 534.

${ }^{32}$ TALAMINI, Eduardo. Questões prejudiciais e coisa julgada. Informativo Justen, Pereira, Oliveira e Talamini, Curitiba, n.109, 2016. Disponível em: Acesso em: 21 mai. 2020. 
mostre relevante ao cabimento do pedido. Pensar diferente seria ignorar os propósitos da atribuição de coisa julgada as questões prejudiciais, especialmente a economia processual e simplificação procedimental. Desta forma, voltando ao exemplo anteriormente exposto, a filiação seria atingida pela coisa julgada, partindo-se da conclusão que foi relevante para a resolução da causa de herança. ${ }^{33}$

\subsection{Segundo pressuposto: Decisão expressa e incidental}

Este pressuposto está expresso no art. 503, parágrafo $1^{\circ}$ do CPC15, cabendo ao julgador manifestar-se, de forma expressa, clara, analítica e fundamentada, sobre a questão prejudicial. Por isso, caso uma questão seja objeto de debate pelas partes, mas não venha a ser apreciada na decisão, sobre ela não haverá coisa julgada. Todos os requisitos processuais para formarem a existência, a validade e a eficácia da decisão principal, aplicam-se à questão prejudicial. ${ }^{34}$

Ainda, é preciso que tal questão prejudicial seja decidida incidentalmente, não constituindo objeto do "pedido principal". Caso isso ocorra, já haverá a formação da coisa julgada por força do art. 503, caput do CPC15. ${ }^{35}$ Daí advém, a lógica conclusão de que se a questão constituir o próprio objeto principal, haverá coisa julgada, mas não por força dos parágrafos $1^{\circ}$ e $2^{\circ}$ do art. 503, mas pelo seu próprio “caput", eis que se estará diante da própria questão de mérito daquela demanda judicial.

Nesse sentido, dever-se-ia conhecer de embargos de declaração para suprir omissão acerca de eventual questão prejudicial não analisada pelo magistrado, o que se defende com base em dois argumentos. Primeiro porque, por sua própria natureza induz a possibilidade de infirmar em resultado diverso, caso analisada, tornando nula a decisão que se omite nesse ponto, nos termos do art. 489, parágrafo $1^{\circ}$, inciso IV do CPC15. E segundo, porque se o sistema do CPC15 possibilita a coisa julgada de questões prejudiciais, este é um objetivo que pode ser legitimamente perseguido pelo litigante -

\footnotetext{
33 TALAMINI, Eduardo. Questões prejudiciais e coisa julgada. Informativo Justen, Pereira, Oliveira e Talamini, Curitiba, n.109, 2016. Disponível em: Acesso em: 21 mai. 2020.

${ }^{34}$ REDONDO, Bruno Garcia. Questões prejudiciais e limites objetivos da coisa julgada no novo CPC. Revista de Processo, São Paulo; RT, a.40, v. 248, out. 2015. p. 52.

${ }^{35}$ REDONDO, Bruno Garcia. Questões prejudiciais e limites objetivos da coisa julgada no novo CPC. Revista de Processo, São Paulo; RT, a.40, v. 248, out. 2015. p. 52.
} 
seja ele autor ou réu - para que obtenha o melhor pronunciamento judicial possível, no caso, aquele que lhe conferiria maior segurança jurídica, impedindo a repetição de discussão de matéria já dirimida anteriormente.

Conquanto, reconhece-se a existência de autorizadas opiniões doutrinárias contrárias a obrigação de julgamento das questões prejudiciais pelo magistrado, especialmente quando exigida pelo vencedor da demanda, como no caso de De Lucca, para quem, esta interpretação poderia colocar em risco a própria eficiência do sistema, "inundando os tribunais com recursos inúteis e protelatórios", destacando ainda que "se as partes pretendem discutir a questão prejudicial como mérito do processo, basta que tomem a iniciativa de incluí-la nos pedidos ou reconvenham." ${ }^{36}$

De todo modo, ainda que se possa concordar que, em regra, a parte não possa se insurgir contra os fundamentos da demanda por lhe faltar interesse recursal, não se pode olvidar que está, se trata de regra geral que admite exceções, como no caso das ações civis públicas quando diante de improcedência por falta de provas, pode o réu interpor recurso visando modificar o motivo da decisão, objetivando a formação de coisa julgada, em busca de sua eficácia preclusiva e, consequentemente, de segurança jurídica ${ }^{37}$. A situação aqui parece idêntica, de modo que caberia a insurgência recursal sobre ponto prejudicial, ainda que o recorrente tenha saído vencedor da demanda principal, uma vez que é permitido a parte que busque o melhor resultado possível, que diante do novo regramento é aquele capaz de produzir coisa julgada sobre o maior número de questões possíveis.

\subsection{Terceiro pressuposto: Contraditório prévio e efetivo}

\footnotetext{
${ }^{36}$ DE LUCCA, Rodrigo Ramina. Os limites objetivos da coisa julgada no novo Código de Processo Civil. Revista de Processo. vol, 2016, 252. p.15.

${ }^{37}$ Pense-se, e.g., no caso de em uma "ação civil pública" o pedido do autor ser julgado improcedente por insuficiência de provas. O demandado, ainda que tecnicamente possa ser tido como vencedor, terá interesse em recorrer se, em sua impugnação à sentença, postular a reforma da decisão para que se declare que o pedido é improcedente por não ter havido qualquer ato lesivo ao interesse metaindividual que se queria proteger. A utilidade do recurso, in casu, é evidente, já que a sentença de improcedência por insuficiência de provas, em sede de "ação civil pública", não é capaz de alcançar a autoridade de coisa julgada material. A sentença que julgue o pedido improcedente por fundamento diverso desse, porém, é perfeitamente capaz de alcançar a auctoritas rei iudicatce. Há, pois, interesse em recorrer. CÂMARA, Alexandre Freitas. Requisitos de admissibilidade dos recursos civis. Dos Recursos. V, 2010, 1.
} 
Tal pressuposto é base de todo o processo democrático positivado no CPC15, com isso o legislador mostrou a preocupação em garantir mais uma vez a participação das partes no processo jurisdicional. Isso decorre do fato, de que ninguém poderá ser prejudicado por decisão oriunda de processo onde não se pode efetuar um contraditório justo e adequado. ${ }^{38}$

A exigência mostra clara congruência com os princípios gerais do direito processual civil, anunciados logo no capítulo I do primeiro livro do CPC15, do qual se extrai, dentre outras disposições de clara inspiração constitucional (como não deixa dúvidas a redação do art. $1^{\circ}$ ), a previsão do que se tem chamado de contraditório efetivo ${ }^{39}$, por meio da aplicação conjunta dos arts, $7^{\circ}, 9^{\circ}, 10^{\circ}$ do Código.

É justamente a previsão expressa de necessidade de contraditório prévio e efetivo - a respeito de uma razão que esteja a sustentar o pleito de tutela jurisdicional por ela formulado ${ }^{40}$ - como condição para que a questão prejudicial seja atingida pela coisa julgada que fez com que o legislador se permitisse suprir a necessidade de pedido expresso da parte. ${ }^{41}$

Essa possibilidade de contraditório prévio e efetivo, determina que seja diferida às partes seu direito de influenciar na decisão. Relata-se justamente a "possibilidade" de coibir que a inércia da parte na defesa de seus interesses se torne um embaraço para afastar a formação da coisa julgada. Tal motivo, levou o CPC15 a prever de maneira expressa, que não haverá coisa julgada sobre a questão prejudicial em caso de revelia. ${ }^{42}$

Nesse ponto Minami e Peixoto esclarecem que por opção legislativa, com o escopo de valorizar o contraditório, a mera revelia, entendida como o mero ato-fato de não contestar, impede, em regra, a formação de coisa julgada sobre questão prejudicial, "sendo irrelevante que sejam agregados outros efeitos jurídicos, como a presunção de

\footnotetext{
${ }^{38}$ DIDIER JR., Fredie. Extensão da coisa julgada à resolução da questão prejudicial incidental no novo Código de Processo Civil brasileiro. Civil Procedure Review, v.6, n.1, p.88, 2015.

${ }^{39}$ GRECO, Leonardo. Contraditório efetivo. Revista Eletrônica de Direito Processual, V. 15(15), 2015.

${ }^{40}$ REICHELT, Luis Alberto. "Decisão sobre questões prejudiciais de mérito e direito fundamental à intangibilidade da coisa julgada material no novo Código de Processo Civil." Revista de processo. No. 259. 2016. p. 4.

${ }^{41}$ LUCON, Paulo Henrique dos Santos. Tutela ao contraditório: Vedação à decisão-surpresa; requisitos para extensão dos limites objetivos da coisa julgada; identificação das decisões imotivadas. In: Panorama Atual do Novo CPC 2. Coordenação: Paulo Henrique dos Santos Lucon e Pedro Miranda de Oliveira. Florianópolis: Empório do Direito, 2017.

${ }^{42}$ LUCCA, Rodrigo Ramina de. Os limites objetivos da coisa julgada no novo Código de Processo Civil. In: Revista de Processo, vol. 252. São Paulo: Revista dos Tribunais, 2016, p. 84.
} 
veracidade". ${ }^{43}$ Os mesmos autores destacam ainda que a controvérsia em si não pode ser considerada requisito para que os efeitos da coisa julgada material deixem de operar sobre a questão prejudicial, na medida em que a limitação à coisa julgada em caso de revelia não se dá pela falta da controvérsia, mas do contraditório efetivo.

A opção do legislador não ficou inerte a críticas, pois a revelia não impede definitivamente o contraditório, caso o réu tenha ciência de demanda contra si proposta e deliberadamente ausentou-se do processo, neste caso haverá a manifestação de seu contraditório. ${ }^{44}$

Nesse ponto, conclui-se que não haverá formação de coisa julgada sobre questão ou ponto prejudicial quando se tratar de uma revelia "qualificada", ou seja, caso o réu for revel e, além disso, tiver ocorrido a produção do efeito material da revelia e o réu não conseguir, por meio de objeção antes do deferimento da sentença, controverter, substancialmente, a questão prejudicial. Por esse ângulo, somente nessa escassa hipótese é que não se efetivou o contraditório prévio e efetivo, motivo pelo qual não se formará coisa julgada. ${ }^{45}$

\subsection{Quarto pressuposto: Competência absoluta do juízo}

$\mathrm{O}$ art. 503, parágrafo $1^{\circ}$, dispõe que o juízo deverá deter competência em razão da matéria e da pessoa para resolver a questão prejudicial como questão principal. De tal forma, a questão incidental decidida ao longo do processo principal, só será atingida pela coisa julgada caso o juízo seja competente para resolvê-la como se principal fosse. Ao contrário, deverá resolver a questão, no entanto, ela não ficará protegida pela coisa julgada. $^{46}$

Vale destacar que a competência a qual se refere o citado dispositivo legal, engloba tanto a competência em razão da matéria quanto da pessoa (art. 503, parágrafo

\footnotetext{
${ }^{43}$ MINAMI, Marcos Youji; PEIXOTO, Ravi. Da questão prejudicial incidental constitucional no STF e o novo regime de coisa julgada. Revista Jurídica da Seção Judiciária de Pernambuco, (10), 277-302. p. 286. ${ }^{44}$ MINAMI, Marcos Youji; PEIXOTO, Ravi. Da questão prejudicial incidental constitucional no STF e o novo regime de coisa julgada. Revista Jurídica da Seção Judiciária de Pernambuco, (10), 277-302. p. 286. ${ }^{45}$ REDONDO, Bruno Garcia. Questões prejudiciais e limites objetivos da coisa julgada no novo CPC. Revista de Processo, São Paulo; RT, a.40, v. 248, out. 2015. p. 53.

${ }^{46}$ DIDIER JR., Fredie. Extensão da coisa julgada à resolução da questão prejudicial incidental no novo Código de Processo Civil brasileiro. Civil Procedure Review, v.6, n.1, 2015. p.88.
} 
$1^{\circ}$, inciso III, do CPC15), de modo que a questão prejudicial só será acobertada pela coisa julgada, se o magistrado tiver competência para resolver a questão prejudicial, caso ela viesse em análise principaliter. ${ }^{47}$

Importante salientar, que o direito brasileiro não regula a remessa do processo, ao juízo competente, para que de lá ocorra o exame da questão prejudicial. Assim, a incompetência não leva à impossibilidade de pronunciamento sobre o tema, apenas obsta que a decisão da questão prejudicial faça coisa julgada. ${ }^{48}$

Didier Jr. destaca ainda uma diferença de tratamento com relação a coisa julgada aplicada as questões principais, na medida em que a incompetência do juízo não obsta de forma absoluta da coisa julgada referente a estas questões, a menos que tal decisão seja submetida ao procedimento da ação rescisória (art. 966, inciso II, do CPC15). ${ }^{49}$

\subsection{Quinto pressuposto: Ausência de limitações probatórias}

O último pressuposto está positivado no art. 503 do CPC15, o qual adverte que a coisa julgada não se estende à questão prejudicial caso, "haja restrições probatórias à cognição que impeçam o aprofundamento da análise da questão prejudicial".

No entanto, Luiz Guilherme Marinoni ${ }^{50}$ exime tal possibilidade, pois a restrição da prova pode resultar de duas técnicas de cognição: a sumária e a exauriente secundum eventum probationis. Na primeira, o juízo deverá decidir com base em mero juízo de probabilidade, dispensando provas, na qual o tempo de produção é incompatível com a urgência que se faz a tutela do direito. Diante disso, não haverá coisa julgada sobre a questão.

De outra forma, a cognição exauriente secundum eventum prabationis, da qual restringe a prova, porém permite que o juiz julgue caso a prova não seja suficiente para

\footnotetext{
${ }^{47}$ MINAMI, Marcos Youji; PEIXOTO, Ravi. Da questão prejudicial incidental constitucional no STF e o novo regime de coisa julgada. Revista Jurídica da Seção Judiciária de Pernambuco, (10), 277-302. p. 286.

${ }^{48}$ TALAMINI, Eduardo. Arts. 502 a 508. In: TUCCI, José Rogério Cruz; FERREIRA FILHO, Manoel Caetano; APRIGLIANO, Ricardo de Carvalho; DOTTI, Rogéria Fagundes; MARTINS, Sandro Gilbert (Coord.). Código de Processo Civil anotado. Rio de Janeiro: GZ Editora, 2016, p. 717.

${ }^{49}$ DIDIER JR., Fredie. Extensão da coisa julgada à resolução da questão prejudicial incidental no novo Código de Processo Civil brasileiro. Civil Procedure Review, v.6, n.1, 2015. p.90.

${ }^{50}$ MARINONI, Luiz Guilherme. Coisa julgada sobre questão, inclusive em benefício de terceiro. Revista de Processo, São Paulo, v.259, 2016. p.100.
} 
elucidar o mérito, pode formar a coisa julgada sobre a questão prejudicial. Lembrando que caso os polos processuais discutam entre si a questão de direito, não haverá necessidade de produção probatória. ${ }^{51}$

Em regra, o procedimento haverá que seguir a ampla instrução probatória e a produção de todos os meios de prova (art.36, do CPC15). Acontece que alguns procedimentos apresentam determinadas restrições probatórias, por força de lei ou fruto da vontade das partes, exemplo do mandado de segurança, que admite apenas prova préconstituída e nas ações possessórias "puras", em que o autor pede a posse com base exclusivamente sobre o direito à posse, e não no direito de propriedade. ${ }^{52}$ Somam-se a estes exemplos, as ações propostas junto aos Juizados Especiais cíveis, procedimento de inventário e partilha e o procedimento de desapropriação. ${ }^{53}$

Richelt ${ }^{54}$ destaca que a distinção que a restrição a qual a lei se refere, nesse ponto, se dá quanto a possibilidade de ampla produção probatória e não necessariamente a sumariedade do procedimento em si. Não é a capacidade de obter-se um resultado judicial com o encurtamento de determinadas fases típicas que impedirá que uma questão prejudicial seja alcançada pela coisa julgada, mas a restrição probatória imposta por determinado procedimento processual específico.

Ainda exemplificando as situações práticas que possam reduzir, Richelt cita a produção de provas nos Juizados Especiais Cíveis, a sumariedade da cognição vertical da tutela de urgência, bem como a limitação cognitiva horizontal como no caso da ação de desapropriação, ações possessórias - no que tange a discussão acerca da propriedade do bem, ações de consignação em pagamento e mandado de segurança, no que concerne a aplicação do art. 19 da Lei 12.016/2009, que permite ao requerente que não obtém sucesso no writ, buscar a satisfação de seus direitos por ação própria. ${ }^{55}$

\footnotetext{
${ }^{51}$ MARINONI, Luiz Guilherme. Coisa julgada sobre questão, inclusive em benefício de terceiro. Revista de Processo, São Paulo, v.259, 2016. p.101.

52 REDONDO, Bruno Garcia. Questões prejudiciais e limites objetivos da coisa julgada no novo CPC. Revista de Processo, São Paulo; RT, a.40, v. 248, out. 2015. p. 58-59.

${ }^{53}$ DIDIER JR., Fredie. Extensão da coisa julgada à resolução da questão prejudicial incidental no novo Código de Processo Civil brasileiro. Civil Procedure Review, v.6, n.1, 2015. p.90.

${ }^{54}$ REICHELT, Luis Alberto. "Decisão sobre questões prejudiciais de mérito e direito fundamental à intangibilidade da coisa julgada material no novo Código de Processo Civil." Revista de Processo. No. 259. 2016. p. 6.

${ }^{55}$ REICHELT, Luis Alberto. "Decisão sobre questões prejudiciais de mérito e direito fundamental à intangibilidade da coisa julgada material no novo Código de Processo Civil." Revista de Processo. No. 259. 2016. p. 6.
} 
Daí que se pode concluir que a aferição acerca da coisa julgada de questão prejudicial não se dá de forma apriorística, dependendo necessariamente de uma análise casuística, capaz de dirimir se naquela situação específica, a capacidade probatória das partes foi de fato restringida pelo procedimento especial. De modo que, em uma ação proposta no juizado especial, em que questão prejudicial que não dependa de prova pericial, tenha sido submetida ao contraditório e expressamente decidida por juiz competente, será capaz de produzir coisa julgada nos termos dos parágrafos $2^{\circ}$ e $3^{\circ}$ do art. 503 do CPC15.

\section{DIREITO COMPARADO: QUESTÕES PREJUDICIAIS E O COLLATERAL ESTOPPEL}

O collateral estoppel recaí sob o capítulo das preclusões no sistema da common law: a teoria da preclusion by prior adjucation engloba as preclusões de rediscutir uma determinada matéria após esta ser julgada e decidida pelo Judiciário. Assim, tal instituto visa garantir a estabilidade das decisões judiciais após seu julgamento, afastando a hipótese de que o mesmo caso seja litigado novamente após seu julgamento por uma corte competente, surgindo, então, como um mecanismo de preservação das decisões jurisdicionais.

O instituto do collateral estoppel não alberga a causa de pedir, atinge a matéria que foi arguida durante o processo, nomeado também de issue preclusion. Não há um determinado conceito para especificar a causa de pedir para esta teoria, sendo que é preciso entender o que dispõe sua restrição e requisitos para que tenha seu efeito preclusivo, mitigando injustiças e ao mesmo tempo respeitando a segurança jurídica e a eficiência do Poder Judiciário estadunidense. Austin Wakeman Scott ${ }^{56}$, diferencia o collateral estoppel da res judicata. Em sua lição, não é o julgamento pelo julgamento que gera a preclusão, mas sim o processo, os pedidos e o pronunciamento do juízo, que seriam ratificados pelo julgamento. Desta maneira, não seria a res judicata que impediria a nova discussão da questão, mas o registro do julgamento.

\footnotetext{
${ }^{56}$ SCOTT, Austin Wakeman. Collateral estoppel by judgment. Harvard Law Review, v.56, n.1, p.4, 1942.
} 
Em síntese, pode-se definir o collateral estoppel como uma construção jurisprudencial do direito estadunidense, da qual limita a possibilidade de se relitigar uma questão já apreciada e decidida no Judiciário. Consequentemente, após certa decisão envolvendo determinada matéria, não será mais possível discuti-la novamente em caso distinto, esperando obter resultado diverso do ocorrido. ${ }^{57}$

O collateral estoppel, não incide sobre a causa de pedir ou no julgamento final do pedido, ele é tido com uma preclusão das questões realmente discutidas no processo. Sintetizando o instituto, este se refere aos efeitos do julgamento sobre o que nele foi arguido. Nesse diapasão, ao dar fim ao litígio, o julgamento emprega uma resposta ao que foi pedido pela parte requerente, seja positiva ou negativa, afetando diretamente a causa de pedir, impedindo que nova ação seja repetida, sob novos argumentos ou fatos trazidos, o julgamento abrangerá o que foi debatido entre as partes. No entanto, caso venham a relitigar entre si em uma ação baseada em nova causa de pedir, o primeiro julgamento terá efeitos sobre as questões já discutidas anteriormente, mesmo que não aparente vínculo com o pedido final. Deste modo, opera sobre o que foi debatido entre as partes, que posteriormente a resposta válida do Judiciário, ficam barradas, ou estopped, de discutir aquela questão novamente. ${ }^{58}$

Em um estudo focalizando a estabilização das premissas do julgamento, Robert Wyness Millar ${ }^{59}$ refutou que a incidência da coisa julgada sobre a conclusão das decisões é um dado generalizado entre os sistemas jurídicos existentes. Entretanto, tratando-se de efeitos da decisão judicial sobre as premissas, há considerável diferença entre os sistemas de direito continental e o anglo-saxão. A divergência entre tais sistemas, ocorre por conta do collateral estoppel, que como já visto permite a imutabilização das questões fáticas e jurídicas resolvidas no fundamento das decisões.

Acontece que a coisa julgada sobre questão prejudicial, positivada a partir da entrada em vigor do CPC15, dispõe similitudes em relação a técnica do collateral estoppel presente no sistema anglo-saxão da common law. ${ }^{60}$ Pois, em ambas técnicas

\footnotetext{
${ }^{57}$ VESTAL, Allan D. Rationale of preclusion. Saint Louis University Law Journal, v.9, p.30, 1964.

${ }^{58}$ SCOTT, Austin Wakeman. Collateral estoppel by judgment. Harvard Law Review, v.56, n.1, p.2, 1942.

${ }^{59}$ MILLAR, Robert Wyness. The premises of the judgement as res judicata in continental and angloamerican law. Michigan Law Review. nov. 1940, v. 39. n. 1, p. 1-36.

${ }^{60}$ MARINONI, Luiz Guilherme. Incidente de resolução de demandas repetitivas. São Paulo: Revista dos Tribunais, 2016. p.21.
} 
ocorre a ênfase na estabilização de questão prejudicial, dissipando que o debate sobre ela seja retomado pelas partes. Ressalva-se, que o collateral estoppel pode abranger as decisões relacionadas a fatos, proibindo sua rediscussão. Já, no direito brasileiro, em contrapartida, o art. 504, incisos I e II do CPC15, detém a regra de que as questões fáticas não são acobertadas pela coisa julgada, portanto não se estabilizam. ${ }^{61}$

Conclui-se, que dá análise dos requisitos para a aplicação do instituto do colateral estoppel, extraem-se semelhanças com os critérios dispostos no art. 503, parágrafos $1^{\circ}$ e $2^{\circ}$ do CPC15, para a incidência da coisa julgada sobre questão prejudicial. Ambas técnicas, impõe como requisito a identidade de questões, as quais devem ter passado pelo crivo do contraditório e sido expressamente decididas, sendo necessário ainda, que a decisão da questão seja imprescindível para o julgamento do mérito. ${ }^{62}$

\section{COISA JUlgada De QUeStões PREJUdiciais E O PRINCíPIO DISPOSITIVO}

Por princípio no direito processual brasileiro, ressalvadas "as questões de ordem pública, cognoscíveis ex officio, não é dado ao juiz, por contingência do princípio dispositivo, conhecer de questões não alegadas pelas partes, tampouco outorgar ao autor algo superior ou inverso do que aquilo por ele requerido". 63

Tal princípio, consiste na regra pelo qual o juiz depende, na instrução da causa, da iniciativa das partes quanto às provas e às alegações em que se fundamentará a decisão: judex secundum allegata et probata partium iudicare debet. Consequentemente, a doutrina nacional aponta que o mais sólido fundamento do princípio dispositivo parece ser a necessidade de salvaguardar a imparcialidade do juiz. O princípio é de inegável sentido liberal, porque a cada um dos sujeitos envolvidos no conflito sub judice é que deve caber o primeiro e mais relevante juízo dos fatos alegados. Sendo assim, acrescer

\footnotetext{
61 TARUFFO, Michele. Collateral estoppel e giudicato sulle questione. parte II. Rivista di diritto processuale. Padova: Cedam, 1972. p. 277.

${ }^{62}$ LOPES, Bruno Vasconcelos Carrilho. A extensão da coisa julgada às questões apreciadas na motivação da sentença. Revista de Processo. São Paulo: Revista dos Tribunais, fev./2013, v. 216, p. 36.

${ }^{63}$ HOFFMANN JUNIOR, Lírio. A teoria da substanciação e seus reflexos sobre a coisa julgada. Panorama atual do novo CPC. Coordenadores: Paulo Henrique dos Santos Lucon e Pedro Miranda de Oliveira. 1. Ed. Florianópolis: Empório do Direito, 2016. p. 261.
} 
excessivamente os poderes do magistrado significaria, em última análise, atenuar a distinção entre processo dispositivo e processo inquisitivo. ${ }^{64}$

A esta prevalência privada na atribuição das principais tarefas relacionadas a condução e instrução do processo, que acaba por gerar a definição privada acerca das matérias a serem abordadas pelo magistrado e se costuma dar o nome de princípio dispositivo, vinculado ao sistema adversarial de processo, enquanto contraponto ao sistema inquisitorial. ${ }^{65}$

Analisando o princípio dispositivo, Rodrigues e Lamy apontam que este “concerne aos limites da lide e à natureza do provimento jurisdicional, pois ao juiz, em princípio, não cabe analisar aquilo que não se pediu ou não analisar aquilo tudo que se pediu, ensejando sentença ultra petita, citra petita ou extra petita" ${ }^{66}$

Os autores destacam que a delimitação do pedido tem caráter dúplice, porquanto nele se definem tanto a natureza quanto a extensão do objeto, de modo que "primeiro se delimita a extensão do pedido, para só então passar-se à delimitação de sua natureza, o que se dá por meio de uma investigação que o operador do direito irá realizar a respeito dos efeitos fáticos e jurídicos que a sentença deverá produzir na vida dos litigantes." 67

A partir desta premissa, Rodrigues e Lamy dividem os pedidos em mediatos e imediatos, sendo estes os meios escolhidos pelo autor e aqueles o objeto de sua pretensão. Desta forma, seguindo o critério de distinção entre meios e fins no processo, apenas os pedidos mediatos estariam ligados ao princípio dispositivo, e, portanto, aptos a gerar nulidade absoluta. Quanto aos pedidos imediatos, os autores defendem que a mera substituição do meio para alcançar o fim almejado pela parte não será apta, por si só, a gerar nulidade, devendo-se aplicar o princípio da fungibilidade. ${ }^{68}$

Como consequência deste princípio, os limites objetivos da coisa julgada deveriam estabelecer estritamente ao pedido e a respectiva causa de pedir formuladas

\footnotetext{
${ }^{64}$ CINTRA. Antônio Carlos de Araújo; GRINOVER. Ada Pellegrini; DINAMARCO. Cândido Rangel. Teoria Geral do Processo. 22 ed. São Paulo: Malheiros Editores Ltda. 2005. p. 70.

65 DIDIER JR, Fredie. Os três modelos de direito processual: inquisitivo, dispositivo e cooperativo. In: Revista de Processo. 2011. p. 208-209

${ }^{66}$ RODRIGUES, Horácio Wanderlei; LAMY, Eduardo de Avelar. Teoria Geral do Processo. 4 ed. rev., atual. e ampl. São Paulo: Atlas, 2016. p. 151.

${ }^{67}$ RODRIGUES, Horácio Wanderlei; LAMY, Eduardo de Avelar. Teoria Geral do Processo. 4 ed. rev., atual. e ampl. São Paulo: Atlas, 2016. p. 152.

${ }^{68}$ Idem.
} 
pelas partes, o que inclusive fundamentava, como já mencionado, a necessidade de propositura da ação declaratória incidental no sistema do CPC73, que fazia com que uma questão prejudicial ganhasse efeitos de pedido "principal”, podendo, a partir de então, se encaixar no interior dos limites objetivos da coisa julgada ${ }^{69}$. No mesmo sentido, Câmara, defende a possibilidade de "concessão de provimento diverso do pleiteado pelo autor, desde que assim se assegure o resultado prático equivalente ao pretendido."70

Theodoro Junior, por sua vez, destaca a estreita ligação entre princípio dispositivo e a garantia de neutralidade do magistrado: "Cabe-lhe receber e solucionar o litígio, tal qual deduzido pelas partes, em juízo, sem ampliações ou derivações para temas não cogitados." ${ }^{, 71} \mathrm{O}$ autor observa que o princípio dispositivo não se abala nem mesmo diante da verificação de questões de ordem pública, eis que estas não serão capazes de ampliar o objeto do pedido ou da causa de pedir, eis que sua cognição deve se dar no limite necessário para solucionar o litígio descrito pelas partes.

Neste modelo, o debate processual se desenvolve com base nos problemas apresentados pelas partes, "em torno do qual gravitam as razões trazidas ao longo da dialética processual", da qual "o pedido, em verdade, é uma proposta de solução apresentada pela parte em face de uma questão a ser decidida pelo juiz no contexto do debate processual." 72

Ao privilegiar a iniciativa privada nos limites objetivos da atuação do magistrado, garante-se uma maior imparcialidade ${ }^{73}$, além de estabelecer limites claros para que tanto o autor quanto o réu saibam previamente e com segurança, quais as questões estão postas "em jogo" e sobre as quais se operará a coisa julgada material.

Com a mudança na legislação expressa nos parágrafos $2^{\circ}$ e $3^{\circ}$ do art. 503 do CPC15, a extensão da coisa julgada material às questões prejudiciais passa a depender da

\footnotetext{
${ }^{69}$ TESHEINER, José Maria Rosa. Teoria geral do processo. 4 ed. São Paulo: Saraiva 2018.p. 376.

${ }^{70}$ CÂMARA, Alexandre Freitas. Liçães de Direito Processual Civil - vol. I. 25. Ed. São Paulo: Atlas, 2014. p. 102.

${ }^{71}$ THEODORO JUNIOR, Humberto. Curso de Direito Processual Civil - vol I: Teoria Geral do Direito Processual Civil, Processo de Conhecimento, Procedimento Comum. 60 ed. Rio de Janeiro: Forense, 2019. p. 72.

${ }^{72}$ REICHELT, Luis Alberto. "Decisão sobre questões prejudiciais de mérito e direito fundamental à intangibilidade da coisa julgada material no novo Código de Processo Civil." Revista de Processo. No. 259. 2016. p. 3.

${ }^{73}$ REICHELT, Luis Alberto. "Decisão sobre questões prejudiciais de mérito e direito fundamental à intangibilidade da coisa julgada material no novo Código de Processo Civil." Revista de Processo. No. 259. 2016. p. 3.
} 
lei, e não mais das partes ${ }^{74}$, o que evidência uma certa guinada para a predominância do interesse público em detrimento do direito privado ${ }^{75}$, que se manifesta no legítimo interesse na não proliferação de demandas e na indesejável possibilidade de incoerências lógicas decorrentes de decisões diferentes sobre questões idênticas, embora prejudiciais.

De Lucca questiona a conclusão de que o princípio dispositivo seria corolário lógico de um modelo processual privatista, alertando que nem toda situação que beneficie o Estado será, apenas por isso, de interesse público, da mesma forma que nem toda situação que o prejudica contrairia o interesse público. E assim concluí que: "A inércia jurisdicional e o princípio dispositivo são inestimáveis conquistas históricas de racionalidade e imparcialidade no julgamento que não podem, jamais, ser tidas pejorativamente por privatistas." 76

Cintra, Grinover e Dinarmarco, respaldam que o processo civil contemporâneo, não é mais eminentemente dispositivo, como era outrora, imperando o princípio da livre investigação das provas, embora com doses maiores de dispositividade. Esta, na visão dos autores, é uma tendência universal, pois o sistema da livre investigação não é devido a particulares regimes políticos, existentes em vários Estados liberais (ex: Áustria, Suíça, França, Inglaterra), do qual no Brasil já se conhecia desde o código estadual da Bahia, de $1915 .{ }^{77}$

Especificamente quanto a ampliação dos limites objetivos da coisa julgada, que passa a abranger as questões prejudicais desde que preenchidos os requisitos legais, Reichelt ${ }^{78}$ enxerga ofensa ao princípio dispositivo, por ferir o que chama de "uma das mais importantes dimensões do princípio dispositivo, que é o princípio da congruência, no qual se busca encontrar um limite ao exercício da jurisdição". Para o autor, assume-se a partir de então, um risco maior para às partes que poderão ser atingidas pela coisa julgada relativa a questões não postas exatamente a julgamento como questões principais.

\footnotetext{
${ }^{74}$ TESHEINER, José Maria Rosa. Teoria geral do Processo. 4 ed.. São Paulo: Saraiva 2018.p. 377.

${ }^{75}$ DE LUCCA, Rodrigo Ramina. Os limites objetivos da coisa julgada no novo Código de Processo Civil. Revista de Processo. vol, 2016, 252. p.15.

${ }^{76}$ DE LUCCA, Rodrigo Ramina. Os limites objetivos da coisa julgada no novo Código de Processo Civil. Revista de Processo. vol, 2016, 252. p.15.

${ }^{77}$ CINTRA. Antônio Carlos de Araújo; GRINOVER. Ada Pellegrini; DINAMARCO. Cândido Rangel. Teoria Geral do Processo. 22 ed. São Paulo: Malheiros Editores Ltda. 2005. p. 72.

${ }^{78}$ REICHELT, Luis Alberto. "Decisão sobre questões prejudiciais de mérito e direito fundamental à intangibilidade da coisa julgada material no novo Código de Processo Civil." Revista de Processo. No. 259. 2016. p. 3.
} 
Justamente por isso, reforça a importância que se deve dar a existência do contraditório prévio e efetivo, que incute ao magistrado a tarefa de "zelar para que não seja proferida decisão nos autos cujo teor possa surpreender as partes, o que feriria de morte o espírito democrático que deve pautar o debate processual"79

De Lucca, enxerga a questão de maneira oposta, ao defender que "A extensão dos limites objetivos da coisa julgada não viola o princípio dispositivo ou a inércia jurisdicional e não está ligada à sobreposição do interesse público sobre o privado." ${ }^{80}$ No seu mister, trata-se de mera opção legislativa em busca de maior efetividade ao processo e que, na prática, em nada restringe a liberdade das partes.

Didier Junior, por sua vez, defende que dificilmente um sistema poderá ser considerado inteiramente dispositivo ou inquisitorial, de modo que o que lhe caracteriza é a presença de instrumentos que predominem mais ou menos a presença de um dos modelos. E vai além, destacando que ambos modelos começam a ser superados pela ideia de um processo cooperativo, que parece ter sido apreendido em vários aspectos pelo $\mathrm{CPC} 15$, que se caracteriza da seguinte forma:

A condução do processo deixa de ser determinada pela vontade das partes (marca do processo liberal dispositivo). Também não se pode afirmar que há uma condução inquisitorial do processo pelo órgão jurisdicional, em posição assimétrica em relação às partes. Busca-se uma condução cooperativa do processo, sem destaques a algum dos sujeitos processuais. ${ }^{81}$

Mitidiero $^{82}$ verifica que há quem conclua que a colaboração no processo civil, é um modelo que resulta da superação dos modelos dispositivo e inquisitório. Todavia, o mais adequado seria se apoiar nos modelos isonômico e assimétrico, basicamente por duas razões: em primeiro lugar, porque o "dispositivo" e "inquisitório" são modelos que retratam apenas o aspecto ligado às posições jurídicas das partes e do juiz no que tange à condução do processo, deixando na sombra outros elementos importantes de comparação entre os modelos (ex: o papel da lógica da boa-fé ao longo do processo). Em segundo lugar, porque o processo civil pautado pela colaboração conserva tanto traços dispositivos

\footnotetext{
${ }^{79}$ Idem. p. 5.

${ }^{80}$ DE LUCCA, Rodrigo Ramina. Os limites objetivos da coisa julgada no novo Código de Processo Civil. Revista de Processo. vol, 2016, 252. p.15

${ }^{81}$ DIDIER JR, Fredie. Os três modelos de direito processual: inquisitivo, dispositivo e cooperativo. In: Revista de processo. 2011. p. 212.

${ }^{82}$ MITIDIERO, Daniel. Colaboração no processo Civil: pressuposto sociais, lógicos e éticos. 1 ed. São Paulo: Editora Revista dos Tribunais, 2015. (livro digital)
} 
(ex: possibilidade de formalização pela aplicação das regras que regem o ônus da prova, art. 373 do CPC15) como traços inquisitórios (ex: a possibilidade de instrução de ofício pelo magistrado, art. 370, do CPC15).

Neste contexto, Granado e Cota Filho defendem ser necessária uma releitura do princípio dispositivo em face do Código de Processo Civil de 2015, que o flexibilizou neste ponto, relativizando o caráter privado da delimitação do alcance objetivo da demanda judicial, sem, contudo, afastar este princípio, que continua a marcar a regra no direito civil:

[...]não cabe mais exclusiva e privativamente à parte decidir sobre o que recairá a autoridade da coisa julgada, mas sim a um conjunto de fatores, entre eles, às assertivas formuladas, à controvérsia realizada, e, então, ao preenchimento dos requisitos presentes nos incisos do parágrafo primeiro do artigo 503, devendo, a partir deste momento, recair sim a autoridade da coisa julgada sobre a questão prejudicial não obstante a falta de pedido das partes. ${ }^{83}$

Assim, se a possibilidade de se aplicar os efeitos da cosia julgada material às questões prejudiciais quebra um paradigma histórico do Direito Processual Civil brasileiro, não se pode dizer que isto ocorre ao arrepio dos princípios constitucionais que lhe dão sustentação. Isto porque, o legislador parece ter se encarregado de tomar os cuidados necessários para evitar que a pretexto de tornar o processo mais célere, eficiente e racional, se olvidasse das garantias democráticas do processo, ligadas a participação efetiva, a ampla defesa e ao contraditório efetivo, termo inclusive empregado textualmente como condicionante para a formação da coisa julgada sobre questão prejudicial.

Essa novidade legislativa, posta como está, sem dúvida exige maior atenção por parte dos operadores do direito, que não poderão alegar surpresa quanto a ela, de modo que como alerta Lucon, "é evidente que tal instituto faz com que a litigância em juízo se torne uma atividade sobre a qual se requer mais atenção e técnica." 84

\footnotetext{
${ }^{83}$ GRANADO, Daniel Willian; COTA FILHO, Fernando Rey. A coisa julgada sobre questões prejudiciais - um olhar sobre o CPC/1939 e o CPC/2015. Revista Jurídica Luso-Brasileira. Ano 5. N. 4, 2019.

${ }^{84}$ LUCON, Paulo Henrique dos Santos. Tutela ao contraditório: Vedação à decisão-surpresa; requisitos para extensão dos limites objetivos da coisa julgada; identificação das decisões imotivadas. In: Panorama Atual do Novo CPC 2. Coordenação: Paulo Henrique dos Santos Lucon e Pedro Miranda de Oliveira. Florianópolis: Empório do Direito, 2017. p. 383.
} 
Daí que, considerando que as questões prejudiciais se ligam, por sua própria natureza, aos pedidos formulados pelas partes - cujo controle continua pertencendo apenas a estas - é dever da parte antever as circunstâncias que poderão se transformar em questões prejudiciais e que, portanto, poderão ser abrangidas pela coisa julgada material.

\section{CONCLUSÃO}

Pode-se perceber que ao longo da história processual nacional, mudanças de paradigmas ocorreram em relação a variados institutos, culminando em um modelo cooperativo de processo civil (CPC15, art. $\left.6^{\circ}\right)$, mitigando a figura do juiz como influência central do litígio, de maneira a colocá-lo em iguais parâmetros com as partes, priorizandose o diálogo e elevando-se o princípio do contraditório em seu grau máximo

Buscou-se estabelecer parâmetros, a partir dos quais a conduta da sociedade se baseará. Assim, o processo contemporâneo deve ser visto como um instrumento cada vez mais ligado a segurança jurídica, capaz de garantir a dignidade da pessoa humana, a liberdade e à igualdade.

Quanto a coisa julgada, é certo que esta importa tanto ao interesse público - pela necessidade de coerência e racionalidade dos processos judiciais, - quanto à tutela dos direitos de particulares, que empregam ao Poder Judiciário suas pretensões e dele esperam obter uma tutela segura, seja ela positiva ou negativa. Desta maneira, o CPC15 parece cumprir a tarefa de sopesar a natureza pública de sua prestação jurisdicional com os interesses privados dos particulares, que se reflete na disponibilidade processual (princípio dispositivo).

No decorrer da pesquisa, pode-se perceber a instabilidade que rodeava o acobertamento da coisa julgada nas questões prejudiciais. Na seara do CPC39, o legislador estabeleceu um sistema bastante obscuro quando a incidência objetiva da autoridade da coisa julgada. Já no Código Buzaid, adotou-se um regime no qual estagnouse as dúvidas, privilegiando-se as partes, em decorrência a adesão do princípio dispositivo. Portanto, na vigência do diploma processual de 1973, apenas as questões que eram deduzidas como pretensões principais ficavam abrangidas pela coisa julgada, 
ressaltando-se que eram as partes que possuíam o monopólio de determinar os limites da coisa julgada.

$\mathrm{O}$ atual $\mathrm{CPC} 15$, trouxe significativas mudanças no sistema de estabilidades no ordenamento jurídico brasileiro, de tal maneira passou a sobre valorizar o debate desenvolvido pelas partes, sendo que suas pretensões não ficam somente engessadas na causa de pedir diretamente ligado ao pedido principal, na medida em que ao decorrer do processo, diferentes questões poderão ser levantadas e dialogadas, para que assim o magistrado possa aplicar sua sentença.

Dentre tais questões, o Código priorizou as questões prejudiciais, entendendo serem essenciais para a resolução do pedido principal. Estas, então, passaram a ser acobertadas pela coisa julgada, tornando-se imutáveis, buscando-se a desejada segurança jurídica, evitando-se assim inconsistências ocorridas nos diplomas antepassados.

Por conseguinte, houve uma aproximação do sistema jurídico nacional, ao instituto da common law - o colateral estoppel, pois em referência a este mecanismo, pode-se perceber que no direito estadunidense, ele é responsável por evitar que as partes voltem a litigar eventual questão já suscitada ao longo de um determinado processo e julgada por um juiz competente. Analogamente, isso passou a acontecer com as questões prejudiciais na jurisdição brasileira, naturalmente respeitando os limites impostos pelo art. 503 do CPC15. Tal opção feita pelo legislador teve como escopo, aumentar a estabilidade das decisões judiciais, a coerência do direito e a credibilidade do Judiciário.

Diante de tais premissas e, considerando o princípio dispositivo ora analisado e debatido ao longo do trabalho, chega-se à conclusão que o atual diploma processual, em se tratando do instituto da formação de coisa julgada em questões prejudiciais, abstevese de afrontar o princípio dispositivo. Isto porque, angariou as devidas precauções necessárias, evitando que as vantagens obtidas como a da maior celeridade, eficiência e redução na possibilidade de decisões contraditórias, não fossem conquistadas às custas do princípio democrático do processo, garantindo necessariamente o contraditório prévio e efetivo na formação de coisa julgada nas questões prejudiciais. No mais, ao dar às partes certa liberdade por selecionar as questões que entendam ser relevantes em seus processos, o princípio dispositivo é respeitado, uma vez que às partes ainda detêm certo controle do que é alegado em juízo. 
Consequentemente, a extensão da coisa julgada sobre as questões prejudiciais, reluz em certos benefícios ao sistema jurisdicional, fazendo com que a questão seja julgada apenas uma vez, ocorrendo significativa economia processual, prevenindo que a parte fique sujeita a ser demandada inúmeras vezes por questões já decididas em causa que permitiu o debate completo onde foi garantido a todas às partes o acesso efetivo a ampla defesa e contraditório.

\section{REFERÊNCIAS:}

ALVIM, Arruda. Ação declaratória incidental. In: WAMBIER, Luiz Rodrigues; WAMBIER, Teresa Arruda Alvim (Org.). Doutrinas Essenciais Processo Civil. v. II. São Paulo: Revista dos Tribunais, 2011.

CÂMARA, Alexandre Freitas. Lições de Direito Processual Civil - vol. I. 25. Ed. São Paulo: Atlas, 2014.

CÂMARA, Alexandre Freitas. Requisitos de admissibilidade dos recursos civis. Dos Recursos. V, 2010, 1.

CARNELUTTI, Francesco. Sistema del diritto processuale civile. v. I. Milano: Padova, 1938.

CHIOVENDA, Giuseppe. Saggi di diritto processuale civile. v. II. Milano: Giuffrè, 1993.

CINTRA. Antônio Carlos de Araújo; GRINOVER. Ada Pellegrini; DINAMARCO. Cândido Rangel. Teoria Geral do Processo. 22 ed. São Paulo: Malheiros Editores Ltda. 2005.

DE LUCCA, Rodrigo Ramina. Os limites objetivos da coisa julgada no novo Código de Processo Civil. Revista de Processo. Vol 252, 2016.

DIDIER JR, Fredie. Os três modelos de direito processual: inquisitivo, dispositivo e cooperativo. In: Revista de processo. 2011.

DIDIER JR., Fredie. Extensão da coisa julgada à resolução da questão prejudicial incidental no novo Código de Processo Civil brasileiro. Civil Procedure Review, v.6, n.1, 2015.

DIDIER jr., Fredie; BRAGA, Paulo Sarno; OLIVEIRA, Rafael. Curso de direito processual civil. 10.ed. Salvador: JUSPodivm, 2015, v.2. 
FABRÍCIO, Adroaldo Furtado. A ação declaratória incidental. Rio de Janeiro: Forense, 1976.

GRANADO, Daniel Willian; COTA FILHO, Fernando Rey. A coisa julgada sobre questões prejudiciais - um olhar sobre o CPC/1939 e o CPC/2015. Revista Jurídica Luso-Brasileira. Ano 5. N. 4, 2019.

GRECO, Leonardo. Contraditório efetivo. Revista Eletrônica de Direito Processual, V. 15(15), 2015.

HOFFMANN JUNIOR, Lírio. A teoria da substanciação e seus reflexos sobre a coisa julgada. Panorama atual do novo CPC. Coordenadores: Paulo Henrique dos Santos Lucon e Pedro Miranda de Oliveira. 1. Ed. Florianópolis: Empório do Direito, 2016.

LOPES, Bruno Vasconcelos Carrilho. A extensão da coisa julgada às questões apreciadas na motivação da sentença. Revista de Processo. São Paulo: Revista dos Tribunais, fev./2013, v. 216.

LUCCA, Rodrigo Ramina de. Os limites objetivos da coisa julgada no novo Código de Processo Civil. In: Revista de Processo, vol. 252. São Paulo: Revista dos Tribunais, 2016.

LUCON, Paulo Henrique dos Santos. Tutela ao contraditório: Vedação à decisãosurpresa; requisitos para extensão dos limites objetivos da coisa julgada; identificação das decisões imotivadas. In: Panorama Atual do Novo CPC 2. Coordenação: Paulo Henrique dos Santos Lucon e Pedro Miranda de Oliveira. Florianópolis: Empório do Direito, 2017.

MARINONI, Luiz Guilherme. Coisa julgada sobre questão, inclusive em benefício de terceiro. Revista de Processo, São Paulo, v.259, 2016.

MARINONI, Luiz Guilherme. Incidente de resolução de demandas repetitivas. São Paulo: Revista dos Tribunais, 2016.

MARINONI, Luiz Guilherme; ARENHART, Sérgio Cruz; MITIDIERO, Daniel. Novo Código de Processo Civil Comentado. 1. ed. Ver. Atual e ampl. São Paulo: Revista dos Tribunais, 2017.

MILLAR, Robert Wyness. The premises of the judgement as res judicata in continental and anglo-american law. Michigan Law Review. nov. 1940, v. 39. n. 1. 
MINAMI, Marcos Youji; PEIXOTO, Ravi. Da questão prejudicial incidental constitucional no STF e o novo regime de coisa julgada. Revista Jurídica da Seção Judiciária de Pernambuco, (10), 277-302.

MIRANDA, Francisco Cavalcanti Pontes de. Comentários ao código de processo civil. v. V. Rio de Janeiro: Forense, 1974.

MITIDIERO, Daniel. Colaboração no processo Civil: pressuposto sociais, lógicos e éticos. 1 ed. São Paulo: Editora Revista dos Tribunais, 2015.

MOREIRA, José Carlos Barbosa. "Questões prejudiciais e questões preliminares". Direito processual civil - ensaios e pareceres. Rio de Janeiro: Borsoi, 1971.

MOREIRA, José Carlos Barbosa. Coisa julgada - limites objetivos. In: Direito aplicado, vol. II, Rio de Janeiro, 2000.

REDONDO, Bruno Garcia. Questões prejudiciais e limites objetivos da coisa julgada no novo CPC. Revista de Processo, São Paulo; RT, a.40, v. 248, out. 2015.

REICHELT, Luis Alberto. "Decisão sobre questões prejudiciais de mérito e direito fundamental à intangibilidade da coisa julgada material no novo Código de Processo Civil." Revista de processo. No. 259. 2016.

RODRIGUES, Horácio Wanderlei; LAMY, Eduardo de Avelar. Teoria Geral do Processo. 4 ed. rev., atual. e ampl. São Paulo: Atlas, 2016.

SCOTT, Austin Wakeman. Collateral estoppel by judgment. Harvard Law Review, v.56, n.1, p.2, 1942.

TALAMINI, Eduardo. Arts. 502 a 508. In: TUCCI, José Rogério Cruz; FERREIRA FILHO, Manoel Caetano; APRIGLIANO, Ricardo de Carvalho; DOTTI, Rogéria Fagundes; MARTINS, Sandro Gilbert (Coord.). Código de processo civil anotado. Rio de Janeiro: GZ Editora, 2016.

TALAMINI, Eduardo. Questões prejudiciais e coisa julgada. Informativo Justen, Pereira, Oliveira e Talamini, Curitiba, n.109, 2016. Disponível em: Acesso em: 21 mai. 2020.

TARUFFO, Michele. Collateral estoppel e giudicato sulle questione. parte II. Rivista di diritto processuale. Padova: Cedam, 1972.

TESHEINER, José Maria Rosa. Teoria geral do processo. 4 ed.. São Paulo: Saraiva 2018. 
Revista Eletrônica de Direito Processual - REDP.

Rio de Janeiro. Ano 16. Volume 23. Número 1. Janeiro a Abril de 2022

Periódico Quadrimestral da Pós-Graduação Stricto Sensu em Direito Processual da UERJ

Patrono: José Carlos Barbosa Moreira (in mem.). ISSN 1982-7636. pp. 769-798 www.redp.uerj.br

THEODORO JUNIOR, Humberto. Curso de Direito Processual Civil - vol I: Teoria

Geral do Direito Processual Civil, Processo de Conhecimento, Procedimento Comum. 60 ed. Rio de Janeiro: Forense, 2019.

VESTAL, Allan D. Rationale of preclusion. Saint Louis University Law Journal, v.9, p.30, 1964.

WAMBIER, Teresa Arruda Alvim; CONCEIÇÃO, Maria Lúcia Lins; RIBEIRO, Leonardo Ferre da Silva; MELLO, Rogerio Liscastro Torres de. Primeiros comentários ao novo código de processo civil: artigo por artigo. São Paulo: RT, 2015 . 